Christophe Montessuit

Irène Papageorgiou

Lis Campos

René Lerch

\section{Retinoic acids increase expression of GLUT4 in dedifferentiated and hypertrophied cardiac myocytes}

Received: 13 June 2005

Returned for revision: 11 July 2005

Revision received: 12 September 2005

Accepted: 4 October 2005

Published online: 10 November 2005
Dr. Ch. Montessuit, $\mathrm{PhD}(\mathbb{\varangle})$

I. Papageorgiou $\cdot$ L. Campos $\cdot$ R. Lerch

Division of Cardiology

Department of Internal Medicine

Geneva University Hospitals

24 Micheli-du-Crest

1211 Geneva 14, Switzerland

Tel.: +41-22/372 7216

Fax: +41-22/372 7229

E-Mail: christophe.montessuit@hcuge.ch
Abstract Sufficient expression of the insulin-sensitive glucose transporter GLUT4 may be crucial for the survival of cardiac myocytes in situations of stress. Expression of GLUT4 in cardiac myocytes correlates with cell differentiation and is reduced in the hypertrophied and failing myocardium. Adult rat cardiomyocytes (ARC) in primary culture undergo dedifferentiation and reduction of GLUT4 expression. Depending on the culture condition partial redifferentiation and/or hypertrophy follows. All-trans (at) and 9-cis retinoic acids (RA) are morphogenetic agents important for cell differentiation. Both atRA and 9-cisRA restored GLUT4 expression in dedifferentiated ARC, while only 9-cisRA could increase GLUT4 expression in hypertrophic ARC. The effects of RA were associated with improved differentiation of the cardiac myocytes, as assessed from the expression of atrial natriuretic factor and the morphology of the contractile apparatus. In neonatal rat cardiomyocytes, 9-cisRA, but not atRA, stimulated transcription from the glut4 promoter. In conclusion, treatment with RA can restore the down-regulated expression of GLUT4 in cardiomyocytes in association with a partial improvement of the differentiated phenotype.

Key words cardiac myocytes - glucose transporters - retinoic acids - gene expression - transcription

\section{Introduction}

Cardiac myocytes use a variety of substrate for energy production, including free fatty acids, glucose, lactate and ketone bodies. Substrate selection is developmentally regulated. During the perinatal period, substrate metabolism shifts from predominant glycolytic and oxidative utilization of carbohydrates to predominant fatty acid oxidation $[4,15]$. This shift is associated with a change in the expression of a number of regulatory proteins of glucose and fatty acids metabolism [21, 24, 32, 38 ], including glucose transporting proteins. Specifically, the ubiquitous glucose transporter GLUT1 is largely replaced by the insulin-regulated isoform GLUT4 [24, 32,
38], although in the human heart GLUT1 is expressed at a higher level in the adult than the fetal myocardium [25]. Myocardial hypertrophy is associated with changes in glucose metabolism characterized by increased basal glucose uptake and insulin resistance [22,23]. Basal uptake of glucose is mediated by GLUT1, which is expressed at a low level in the normal adult heart, but is increased in rat models in vivo during post-ischemic reperfusion [33] or cardiac failure following remodeling after large myocardial infarction [28]. Conversely, expression of GLUT4 is decreased in these conditions $[28,33]$. Observations in GLUT4-null mice indirectly suggest that down-regulation of GLUT4 may be involved in the pathogenesis of hypertrophy $[1,14]$. In addition, GLUT4-deficiency is associated with impaired post-ischemic recovery [36]. 
Adult rat cardiomyocytes (ARC) in primary culture express markers of hypertrophy, including ANF and $\alpha$ smooth muscle actin, which are normally expressed during fetal and perinatal life, but are down-regulated during maturation [7]. In addition, ARC in primary culture display a rapid down-regulation of GLUT4 expression associated with dedifferentiation. Depending on the culture conditions, GLUT4 expression may either spontaneously recover with partial redifferentiation of ARC, in medium containing low amounts of fetal calf serum (FCS) [20], or remain suppressed during hypertrophy in high FCS-containing medium [27].

Retinoic acids are physiological modulators of differentiation with the ability to blunt the hypertrophic response of neonatal rat cardiac myocytes in vitro [41, 44]. In addition, retinoic acids have been shown to induce the differentiation of $\mathrm{H} 9 \mathrm{c} 2$ myoblasts into cardiac rather than skeletal myocytes [17]. Finally, retinoic acids stimulate the expression of GLUT4 in skeletal myocytes [31]. In the present study, we investigated whether retinoic acids could restore expression of GLUT4 in the two related models of cardiac myocytes dedifferentiation and hypertrophy mentioned above.

\section{Methods}

\section{Animals}

We obtained male Sprague-Dawley rats (100-110 g) from IFFA CREDO (L'Arbresle, France). Newborn SpragueDawley rats (1-3 days) were from the Geneva University School of Medicine animal facility. The ethical committee of the Geneva University School of Medicine and the Geneva State Veterinary Office approved the study protocol, which conforms to the Guide for the Care and Use of Laboratory Animals published by the US National Institutes of Health (NIH Publication No. 85-23, revised 1996).

\section{Adult rat cardiomyocytes culture}

Adult rat cardiomyocytes (ARC) were isolated by retrograde perfusion of the hearts with collagenase (type II, Biochrom) $[5,8]$. Dishes were previously coated with $0.1 \%$ gelatin for $4 \mathrm{~h}$ and incubated overnight with culture medium containing $20 \%$ fetal calf serum (FCS). For immunofluorescence studies, cells were plated on laminin-coated glass coverslips. Cells were plated at a density of approximately $20000 \mathrm{cells} / \mathrm{cm}^{2}$. In the dedifferentiation - redifferentiation model, culture medium was M199 with Earle's salts (Life Technologies) supplemented with $20 \mathrm{mM}$ creatine, $100 \mu \mathrm{M}$ cytosine- $\beta$-D-ara- binofuranoside and $1 \%$ FCS. In the remodeling-hypertrophy model, the same culture medium was supplemented with $10 \%$ FCS.

All-trans (at) and 9-cis retinoic acids (Sigma) and TTNPB (Calbiochem) were added from $1000 \mathrm{X}$ ethanol stock solutions to the medium at the time of plating (day $0)$. The medium was replaced every other day.

\section{Neonatal rat cardiomyocytes culture}

Neonatal rat cardiomyocytes (NRC) were isolated by collagenase digestion [35]. Cells were plated at a density of $2.5 \times 10^{5}$ cells per $3.5-\mathrm{cm}$ dish or $5 \times 10^{5}$ cells per $6-\mathrm{cm}$ dish (day 0 ), transfected on day 1 and treated with atRA, 9cisRA or TTNPB on day 2 for two additional days. Retinoid treatment was administered in M199 supplemented with $20 \mathrm{mM}$ creatine, $100 \mu \mathrm{M}$ cytosine- $\beta$-D-arabinofuranoside and $1 \%$ FCS as in ARC.

\section{Plasmids and NRC transfection}

The plasmid pLuc-GT4 encoding Photinus luciferase under the control of the rat glut4 promoter has been described previously [20]. It was transfected together with a plasmid encoding Renilla luciferase under the control of the SV40 promoter (pRL-SV40, Promega). Transient transfection of NRC was performed using the calcium phosphate precipitation method [35]. Transfection mixes contained $1.5 \mu \mathrm{g}$ of pLuc-GT4 and $1.5 \mu \mathrm{g}$ of pRL-SV40. Photinus and Renilla luciferase activity was measured 2 days after stimulation with retinoids with the Dual Luciferase Reporter kit (Promega).

\section{Immunoblot analysis}

ARC in one 6-cm dish were extracted in $200 \mu$ l RIPA [150 $\mathrm{mM} \mathrm{NaCl}, 9.1 \mathrm{mM} \mathrm{Na}_{2} \mathrm{HPO}_{4}, 1.7 \mathrm{mM} \mathrm{NaH} \mathrm{PO}_{4}, \mathrm{pH}$ 7.4, 1:100 protease inhibitor cocktail (Sigma P8340), $5 \mathrm{mM}$ $\mathrm{NaF}, 10 \mathrm{mM} \mathrm{Na}_{2} \beta$-glycerophosphate, $10 \mathrm{mM} \mathrm{Na}_{2}$ paranitrophenyl phosphate, $1 \mathrm{mM} \mathrm{NaVO}_{3}$ ]. Extracts were clarified by centrifugation (12000 rpm for 5') and supernatants were used for SDS-PAGE and immunoblotting [29]. A monoclonal anti-GLUT4 antibody (clone 1F8) was obtained from ANAWA (Wangen, Switzerland). The

Table 1 RT-PCR primers

GLUT1/4 Forward: $5^{\prime}$-GTCATCAACGCCCC(A/C)CAGAA-3' Reverse: 5'-GAGAAGATGGCCACGGAGAGAG-3'

ANF Forward: $5^{\prime}$-AGTGCGGTGTCCAACACAG-3' Reverse: 5'-CTTCATCGGTCTGCTCGCT-3' 
anti-mouse IgG HRP-conjugated antibody was from Sigma. Blots were revealed by chemiluminescence (ECL, Amersham). Quantitative analysis of bands on films was done by laser densitometry (ImageQuant 3.3, Molecular Dynamics).

\section{RT-PCR analysis}

ARC or NRC in one 6-cm dish were extracted in $1 \mathrm{ml}$ TRIZOL (Life Technologies) and total RNA was purified according to the manufacturer's protocol. $125 \mathrm{ng}$ total RNA was used for reverse transcription and subsequent polymerase chain reaction using the OneStep RT-PCR kit (Qiagen). Primers capable of coamplifying GLUT1 and GLUT4 cDNAs were used (Table 1), which allowed resolving their respective products on the basis of a 12base pair-size difference [30]. For the measurement of ANF expression, 18S rRNA was amplified in the same reaction using primers and competimers from the QuantumRNA kit (Ambion). Cycling conditions were as follows: $30 \mathrm{~min}$ at $50{ }^{\circ} \mathrm{C}$ for reverse transcription, $15 \mathrm{~min}$ at $95^{\circ} \mathrm{C}$ for reverse transcriptase inactivation and polymerase activation followed by 25 cycles of $30 \mathrm{sec}$ at $94^{\circ} \mathrm{C}$, $1 \mathrm{~min}$ at $55^{\circ} \mathrm{C}$ and $1 \mathrm{~min}$ at $72^{\circ} \mathrm{C}$. After a final extension step of $10 \mathrm{~min}$ at $72^{\circ} \mathrm{C}$, PCR products were resolved by electrophoresis on $10 \%$ polyacrylamide gels in $1 \mathrm{X}$ TBE (89 mM Tris-borate, 2 mM EDTA) buffer. The gels were stained with ethidium bromide and a fluorescent image acquired with a digital camera. Quantitative analysis of bands on gel was done with the ImageJ software.

\section{Immunofluorescence}

ARC cultured on glass coverslips were fixed with $4 \%$ paraformaldehyde in PBS and permeabilized with $0.3 \%$ Triton X-100 in PBS. The primary antibody used was directed against sarcomeric $\alpha$-actinin (Sigma A7811). The fluorophore-conjugated secondary antibody was anti-mouse IgG-Alexa588 (Molecular Probes, Eugene, OR). Both antibodies were diluted in PBS containing $1.5 \%$ non-immune goat serum. Counterstaining for Factin was obtained with phalloidin-Alexa536 (Molecular Probes). DNA was stained with TO-PRO3 (Molecular Probes). Slides were mounted with VectaShield (Vector Laboratories) and examined with a Carl Zeiss LSM510 confocal microscope. A $1 \mu \mathrm{M}$-thick confocal slice was acquired at the base of the nuclei, that is at the shoulder of the myofibrillar ball (see below). Images luminosity and contrast were digitally enhanced with Photoshop 3.0.5 (Adobe Systems).

\section{Statistics}

Statistical analyses were performed with the Prism4 software (GraphPad Softwares). Data are presented as mean \pm SEM. Multiple groups were compared by ANOVA followed by Bonferroni's post-hoc test. Differences were considered significant when $\mathrm{p}$ was less than 0.05 . In doseresponse experiments, the $\mathrm{EC}_{50}$ for each agonist was obtained by curve-fitting the average of several experiments and is presented with a $95 \%$ confidence interval.
Fig. 1 Retinoic acids increase GLUT4 expression in the dedifferentiation-redifferentiation model. ARC were isolated and plated in $1 \% \mathrm{FCS}$ medium in the presence of either $10 \mathrm{nM} \mathrm{RA}$ (panels $A$ and B), $100 \mathrm{nM}$ RA (panels $($ and $\mathbf{D}$ ) or the vehicle. Two and 7 days after, plating ARC total RNA and proteins were extracted and the relative expression of the GLUT4 protein (panels $\mathbf{A}$ and $\mathbf{C}$ ) and the GLUT4/GLUT1 mRNA ratio (panels B and $\mathbf{D}$ ) were determined. Results are mean \pm SEM of 14 or more experiments. ${ }^{*} p<0.05$; ${ }^{* *} p<0.01$; *** $p<0.001$ vs. respective control by ANOVA
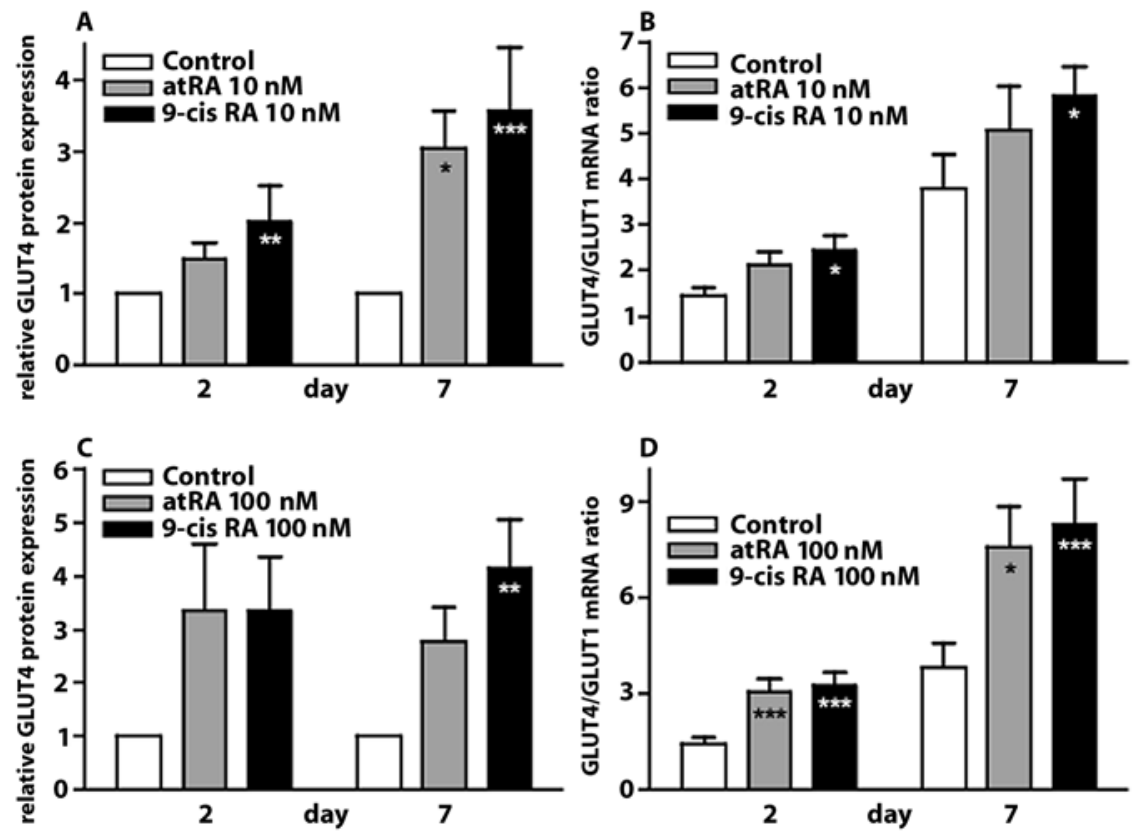
The data were fitted to a sigmoid dose-response equation from the Prism4 equations library.

\section{Results}

\section{Dedifferentiation-redifferentiation model}

In previous experiments, we observed a reduction in GLUT4 expression in ARC in primary culture that was transient in low serum conditions [18]. Treatment of ARC with retinoic acids (RA) (Fig. 1) at concentrations of 10 and $100 \mathrm{nM}$ from the moment of isolation prevented the loss of GLUT4 expression at day 2 and enhanced the recovery of GLUT4 expression at day 7 (Fig. 1). These effects were observed both at the mRNA and at the protein levels and were consistently more robust with 9-cisRA than with atRA. RA did not modify the expression of the glucose transporter GLUT1 (data not shown).

Both atRA and 9-cisRA can activate Retinoic Acid Receptors (RAR), whereas only 9-cisRA activates Retinoid X Receptors (RXR). To gain insight into the type of retinoid receptor involved in the restoration of GLUT4 expression, we constructed dose-response curves (Fig. 2). Half-maximal stimulation of GLUT4 mRNA expression was achieved with a concentration of 9-cisRA that was below that of atRA by one to two orders of magnitude (Table 2). Intriguingly, half-maximal stimulation of GLUT4 protein expression was obtained with a concentration of 9-cisRA that was by two to three orders of
Table $2 \mathrm{EC}_{50}$ of the effect of RA on GLUT4 expression

\begin{tabular}{llll}
\hline & & $\begin{array}{l}\text { GLUT4/GLUT1 } \\
\text { mRNA ratio }\end{array}$ & GLUT4 protein \\
& & & \\
\hline atRA & Day 2 & $26 \mathrm{nM}$ & $28 \mathrm{nM}$ \\
& & $20-33 \mathrm{nM}$ & $25-32 \mathrm{nM}$ \\
& Day 7 & $1.15 \mathrm{nM}$ & $16 \mathrm{nM}$ \\
& & $0.94-1.41 \mathrm{nM}$ & $13-20 \mathrm{nM}$ \\
9-cisRA & Day 2 & $0.69 \mathrm{nM}$ & $88 \mathrm{pM}$ \\
& & $0.51-0.96 \mathrm{nM}$ & $50-154 \mathrm{pM}$ \\
& Day 7 & $0.28 \mathrm{nM}$ & $17 \mathrm{pM}$ \\
& & $0.18-0.43 \mathrm{nM}$ & $13-23 \mathrm{pM}$ \\
\hline
\end{tabular}

magnitude below that of atRA. On the other hand, GLUT4 protein expression declined with the highest dose of 9-cisRA $\left(10^{-6} \mathrm{M}\right)$, which was not taken into account for curve-fitting. Another feature of the dose-response curves was the higher sensitivity to both atRA and 9cisRA by day 7 .

To further assess the role of RAR, we stimulated ARC with the RAR-specific agonist 4-[(E)-2-(5,6,7,8-tetrahydro-5,5,8,8-tetramethyl-2-naphtalenyl)-1-propenyl]benzoic acid (TTNPB) [12]. TTNPB at the dose of $10 \mathrm{nM}$ efficiently increased both the GLUT4/GLUT1 mRNA ratio and the relative expression of the GLUT4 protein (Fig. 3). ANOVA analysis of the data in Fig. 3 indicated an overall highly statistically significant effect of TTNPB ( $p<0.001$ ). However, pair-wise comparison with posthoc Bonferroni's correction achieved significance only for GLUT4 protein expression on day 2 and for GLUT4/ GLUT1mRNA ratio on day 7. The large inter-experimen-
Fig. 2 Dose-response curves of the effects of RA on GLUT4 expression. ARC were isolated and plated in $1 \% \mathrm{FCS}$ medium in the presence of increasing concentrations of RA or the vehicle. Two (panels $\mathbf{A}$ and $\mathbf{B}$ ) and 7 days (panels $\mathbf{C}$ and $\mathbf{D}$ ) after plating, ARC total RNA and proteins were extracted and the relative expression of the GLUT4 protein (panels $\mathbf{A}$ and $\mathbf{C}$ ) and the GLUT4/GLUT1 mRNA ratio (panels $\mathbf{B}$ and $\mathbf{D}$ ) were determined. Results are mean \pm SEM of five or more experiments. Doseresponse curves were fitted as described in Methods: Statistics. EC 50 obtained by curve fitting are presented in Table 2
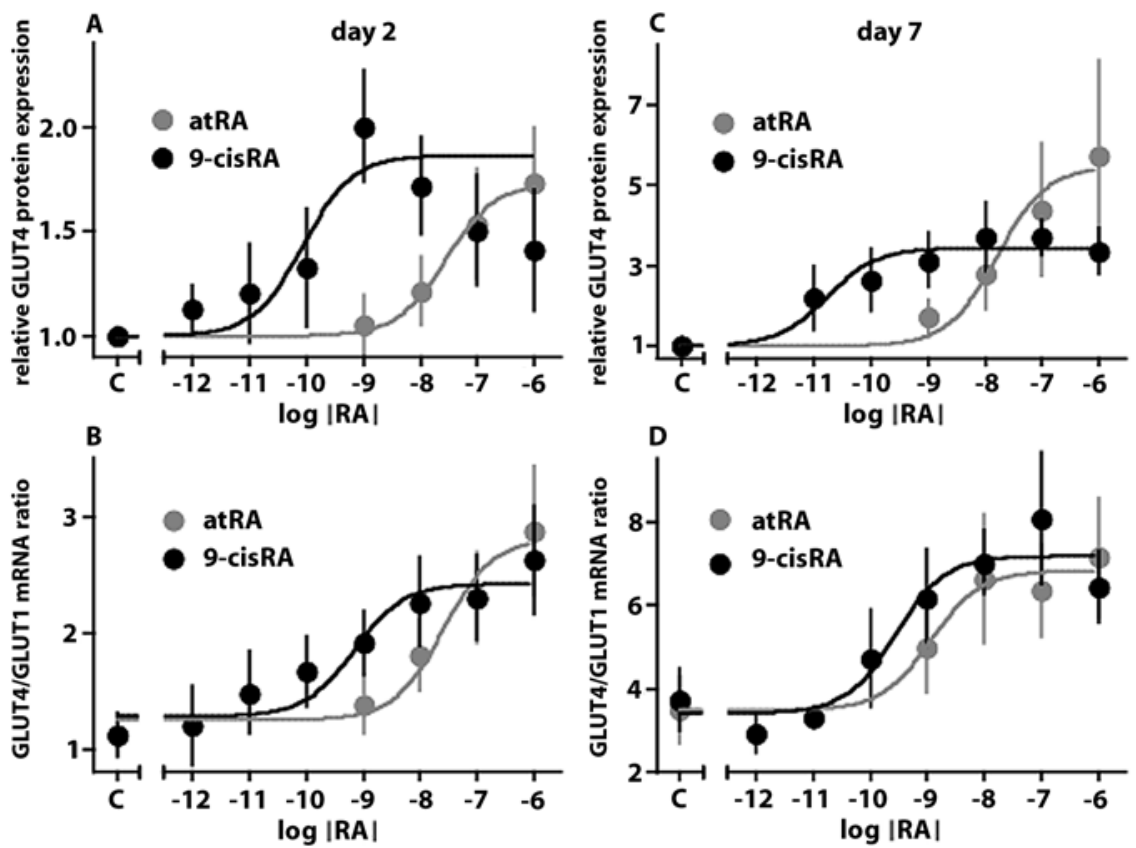
Fig. 3 A RAR-specific agonists increases GLUT4 expression in ARC. ARC were isolated and plated in $1 \% \mathrm{FCS}$ medium in the presence of either $10 \mathrm{nM}$ TTNPB or the vehicle. Two and 7 days after plating, ARC total RNA and proteins were extracted and the relative expression of the GLUT4 protein (left panel) and the GLUT4/GLUT1 mRNA ratio (right panel) were determined. Results are mean \pm SEM of eight or more experiments. ${ }^{* * *} \mathrm{p}<0.001$ vs. respective control by ANOVA
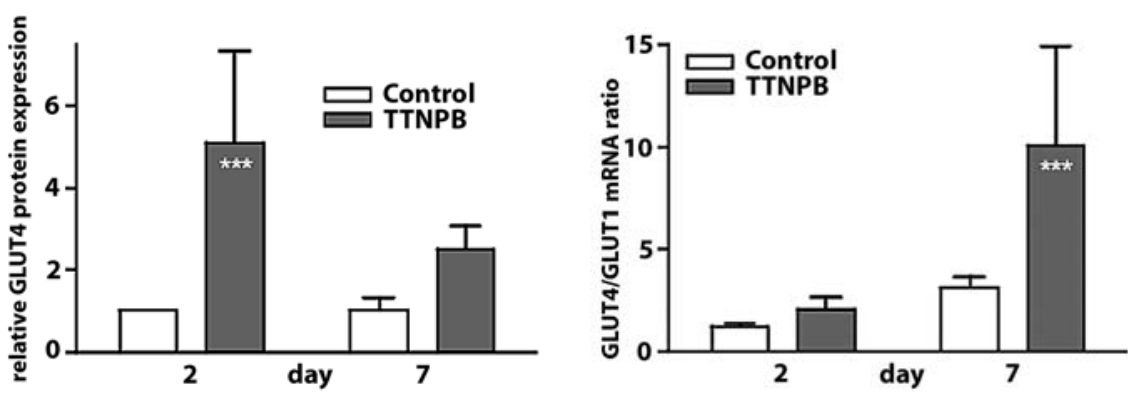

tal variations inherent to primary culture may explain these effects.

Two days following plating of the ARC, cells were either rod-shaped or rounded up by hypercontraction, with only minimal cell spreading. No differences were apparent between control and RA-treated ARC. After 7 days in culture, ARC had started to disassemble the contractile apparatus and spread onto the substratum. A "myofibrillar ball" persisted in the perinuclear region of control ARC (Fig. 4). ARC cultured in the presence of $10 \mathrm{nM}$ of atRA, 9-cis RA or TTNP showed reduced spreading and retained a higher level of sarcomeric organization. ARC treated with $100 \mathrm{nM}$ RA were larger than control cells, but still exhibited a high level of sarcomeric organization.

\section{Remodeling-hypertrophy model}

ARC in primary culture with medium containing a high concentration of FCS (10-20\%) undergo phenotypic changes reminiscent of in vivo hypertrophy. We investi-
Fig. 4 Effects of retinoic acids on cardiac myocytes morphology in the dedifferentiation-redifferentiation model. ARC were isolated and plated in $1 \% \mathrm{FCS}$ medium in the presence of either $10 \mathrm{nM}$ RA or TTNPB, $100 \mathrm{nM}$ RA or the vehicle. Two hours (ex vivo) or 7 days after plating, ARC were fixed and stained for immunofluorescence. Red: F-actin; green: $\alpha$-sarcomeric actinin; blue: nuclear DNA. Scale bar: $50 \mathrm{nM}$
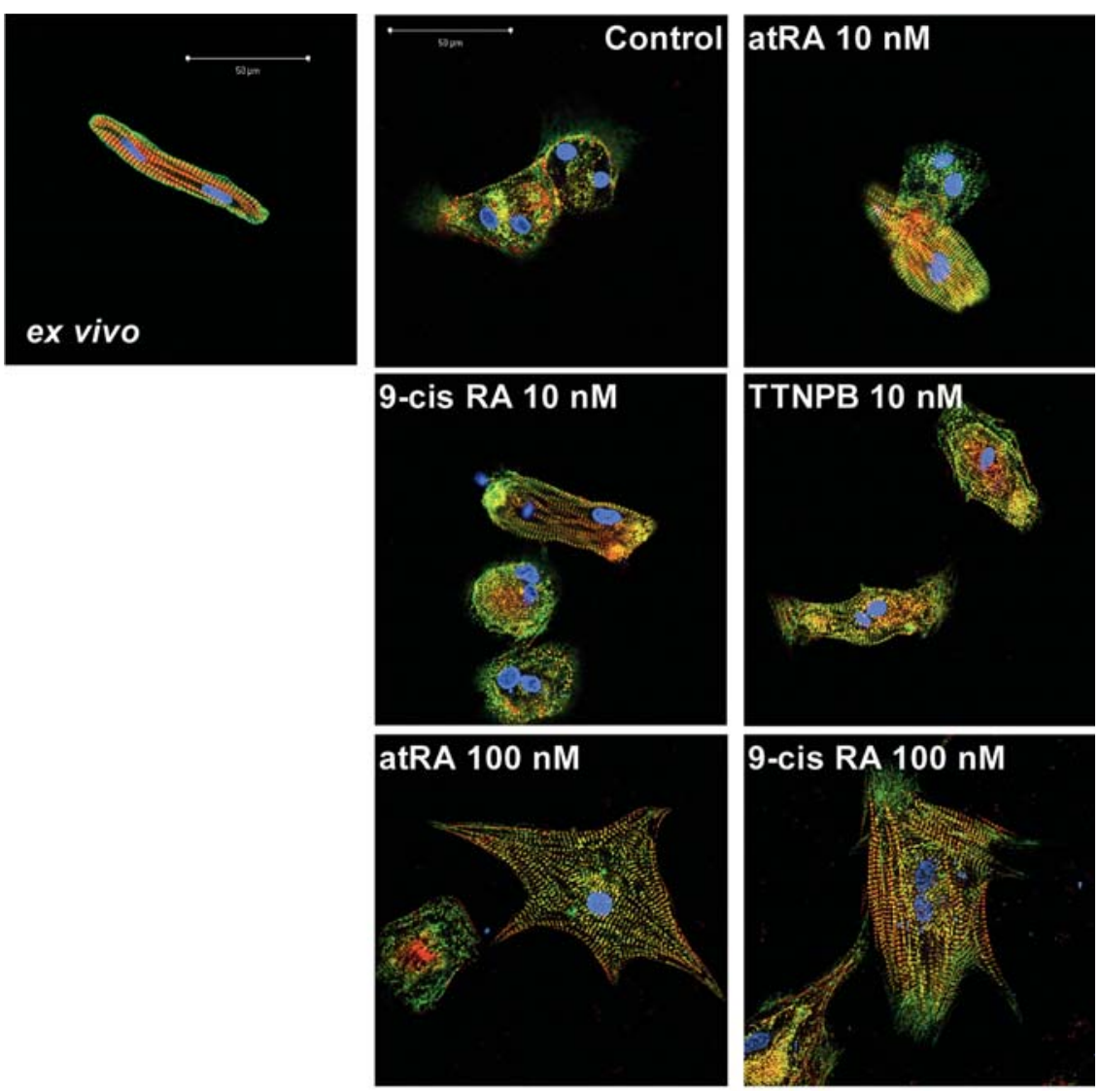
Fig. 5 Retinoic acids reduce initial ANF overexpression and increase myofibrillar organization in hypertrophy. ARC were isolated and plated in $10 \%$ FCS medium in the presence of either 100 nM RA or the vehicle. A Immediately after isolation and after 2, 7 and 14 days, total RNA was extracted and relative ANF mRNA expression determined. Note the logarithmic scale. ${ }^{*} \mathrm{p}<0.05$; ${ }^{* * *} p<0.01$ vs. control at the same time point by ANOVA. Results are mean \pm SEM of nine or more experiments. B Two hours (ex vivo) or 7 days after plating, ARC were fixed and stained for immunofluorescence. Red: F-actin; green: $\alpha$-sarcomeric actinin; blue: nuclear DNA. Scale bar: $50 \mu \mathrm{M}$

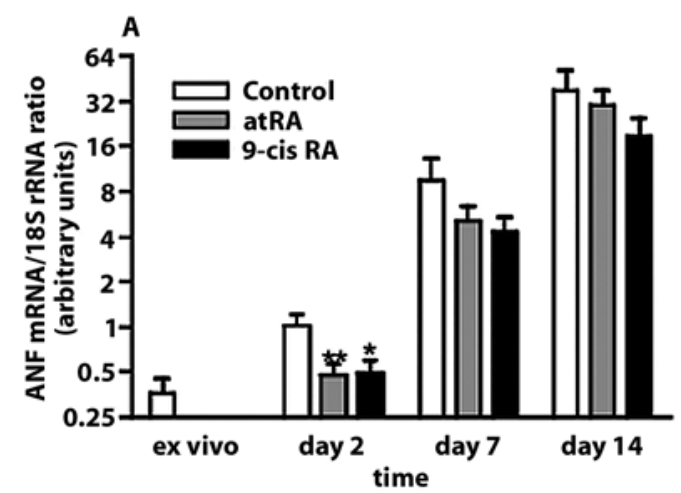

B
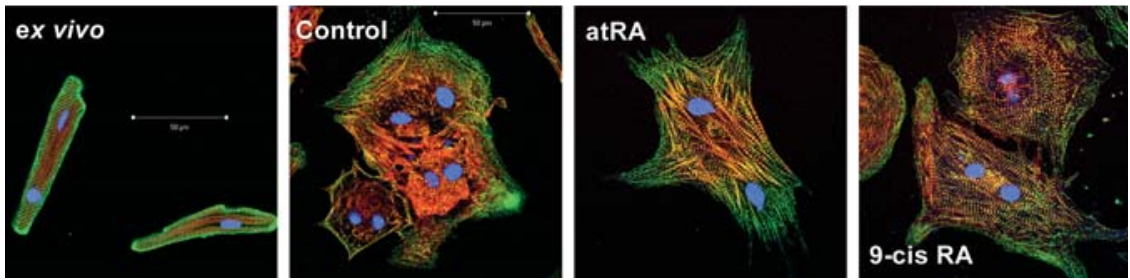

gated the effects of RA on the phenotype of ARC and on GLUT4 expression in this setting.

Inclusion of RA ( $100 \mathrm{nM})$ in the culture medium from the day of plating significantly curbed the increase in ANF expression observed after 2 days in primary culture. Later, by the time hypertrophy fully developed (day 7 and thereafter), there was only a non-significant trend toward reduction of ANF expression (Fig. 5A). Similarly, the notable increase in cell size observed between day 7 and day 14 was not appreciably reduced by treatment with RA (data not shown). However, ARC cultured for 7 days in the presence of RA displayed a more differentiated morphology with increased myofibrillar organization (Fig. 5B). Thus, RA do not seem to prevent hypertrophy, but promote a more differentiated cardiomyocyte phenotype.

In the presence of a high concentration of FCS (10\%), 9-cisRA (100 nM) stimulated the expression of the GLUT4 mRNA at days 2 and 14 (Fig. 6). By day 7, the
GLUT4/GLUT1 mRNA ratio had largely recovered as compared to day 2, perhaps explaining the lack of effect of 9-cisRA at this time point. Expression of the GLUT4 protein in response to 9-cisRA was increased at all time points. Although individual time points did not reach statistical significance, the effect of 9-cisRA throughout the culture period was significant ( $p<0.01$ by ANOVA). In $10 \%$ FCS conditions, atRA failed to affect the expression of GLUT4 at all time points.

\section{Transcriptional effects of retinoic acid}

Because both RAR and RXR belong to the family of nuclear hormone receptors/transcription factors, we determined whether treatment of cardiac myocytes with RA increased transcription from the glut4 promoter. We resorted to neonatal rat cardiomyocytes (NRC) for these experiments because ARC are not amenable to conven-
Fig. 6 Effect of RA on GLUT4 expression in hypertrophy. ARC were isolated and plated in $10 \% \mathrm{FCS}$ medium in the presence of $100 \mathrm{nM}$ atRA, $100 \mathrm{nM}$ 9cisRA or the vehicle. Two, 7 and 14 days after plating, ARC total RNA and proteins were extracted and the relative expression of the GLUT4 protein (top panel) and the GLUT4/GLUT1 mRNA ratio (bottom panel) were determined. Results are mean \pm SEM of ten or more experiments. ${ }^{*} p<0.05$ vs. respective control by ANOVA
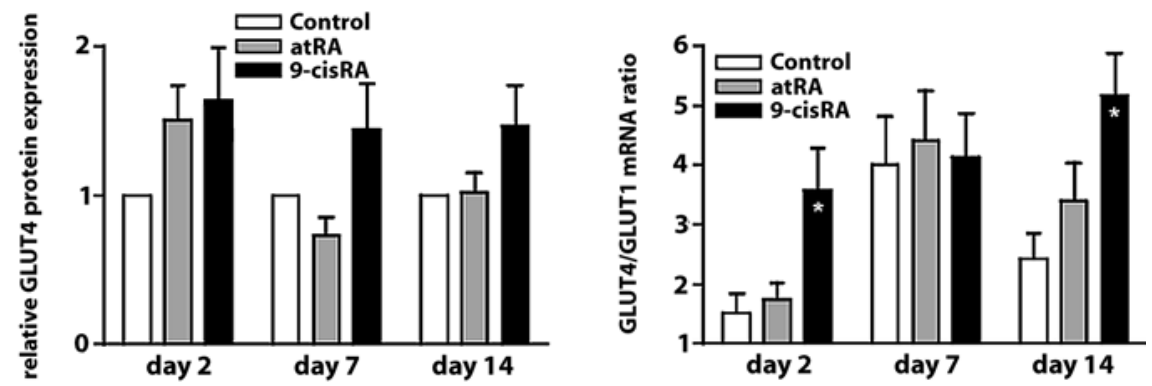
Fig. 7 Effects of RA on GLUT4 expression in neonatal rat cardiomyocytes. NRC were transfected one day after isolation with plasmids encoding luciferase under the control of either the glut 1 or the glut 4 promoter. On day 2, NRC were stimulated with atRA, 9cisRA or TTNPB for two additional days. A NRC total RNA was extracted and the GLUT4/GLUT1 mRNA ratio determined. B NRC were lysed and luciferase expression, indicative of either the glut 1 or the glut 4 promoter activity, was measured in a luminescence-based assay. Results are mean \pm SEM of fourfive experiments. ${ }^{*} p<0.05$ vs. control treatment by ANOVA
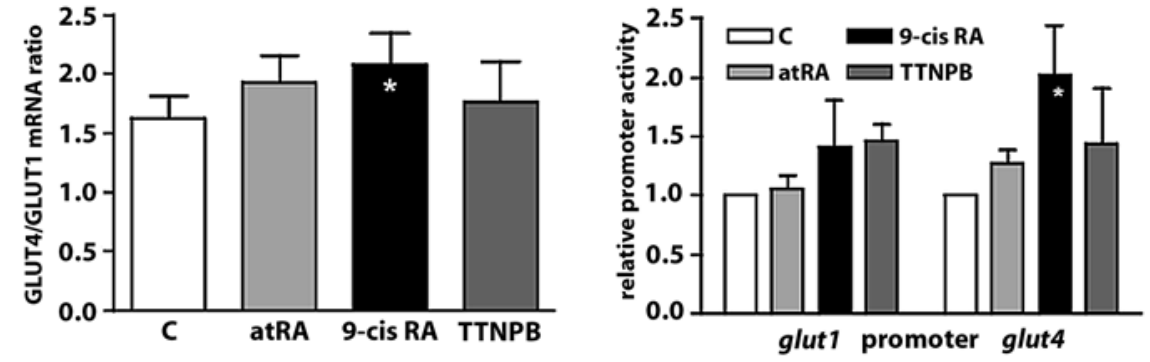

tional transfection techniques. Similar to the situation in ARC, 9-cisRA significantly increased the GLUT4/GLUT1 mRNA ratio in NRC. However, atRA and TTNP failed to alter the GLUT4/GLUT1 mRNA ratio in NRC (Fig. 7A). Accordingly, 9-cisRA clearly stimulated transcription from the glut4 promoter in NRC, whereas neither atRA nor TTNPB had a significant effect (Fig. 7B).

\section{Discussion}

Sufficient expression of the insulin-sensitive glucose transporter GLUT4 may be crucial for the survival of cardiac myocytes in situations of post-ischemic stress [36]. Indeed, GLUT4 translocation during ischemia $[19,42]$ allows for a rapid activation of glycolytic flux early during reperfusion that is important for the restoration of the ionic homeostasis $[10,11]$. Expression of GLUT4 is dependent on cell differentiation in adipocytes [13] and skeletal muscle myocytes [26], as well as in cardiac myocytes [20, 27]. In this series of experiments, we demonstrated that retinoic acids, morphogenetic agents that influence the differentiation of cardiac myocytes, restore the expression of GLUT4 in dedifferentiated and hypertrophic cardiac myocytes. The positive influence of retinoic acids on the differentiation of cardiac myocytes in culture has been demonstrated in different experimental settings such as stem cells $[40,43]$, the H9c2 myoblastic cell line [17] and the HL-1 atrial cell line [39]. In contrast, experiments in stem cells [34] and in embryonic carcinoma cells [9] have shown a repressive effect of retinoic acids on the differentiation of cardiac myocytes. These discrepancies may arise from the different concentrations of retinoic acid used. Studies reporting a differentiating effect of retinoic acids used them at $10^{-9}-10^{-8}$ $M$, whereas in experiments showing anti-differentiation effects of retinoic acids, the concentrations of the agents were $10^{-7}-10^{-6} \mathrm{M}$. This interpretation is consistent with our findings that $\mathrm{EC}_{50}$ for the effect of retinoic acids on
GLUT4 expression were in the nanomolar range, or even in the picomolar range in the case of 9-cisRA.

Little information is available on the effects of retinoic acids on the adult myocardium. Administration of atRA to normal rats induced a slight cardiac hypertrophy with improved contractility [6], while atRA treatment of spontaneously hypertensive (SHR) rats reduced interstitial fibrosis of the myocardium [16].

The regulation of gene expression by retinoic acids is mediated by two subfamilies of receptors from the nuclear receptor/transcription factor family, Retinoid Acid Receptors (RARs) and Retinoid X Receptors (RXRs). 9-cisRA is the bona fide ligand for RXRs, while both all-trans and 9-cisRAs are ligands for the RARs with similar affinities in the nanomolar range $[2,3]$. Therefore, the data obtained in dose-response experiments indicate that increased expression of GLUT4 in response to retinoic acids could very well be mediated by RARs, as RARs are activated by either all-trans or 9-cisRA. However, in the presence of biological membranes, atRA can be partially isomerized to 9-cisRA [37]. Thus, based on the dose-response data we could not rule out that atRA was partially isomerized to 9-cisRA and that only RXRs were involved. In addition, these this mechanisms would explain the largely different apparent $\mathrm{EC}_{50}$ for atRA and 9-cisRA. However, TTNPB, a RAR-specific RA analog, stimulated expression of both the GLUT4 mRNA and protein, pointing to a role of RARs.

As for most nuclear receptors/transcription factors, regulation of gene expression by retinoic acid receptors is thought to mainly involve transcriptional regulation. Using a luciferase reporter transfected into neonatal rat cardiomyocytes (NRC), we observed that only 9-cisRA stimulated transcription from the glut4 promoter, while atRA or TTNPB did not. This result suggests that transcription from the glut4 promoter is under the control of RXR. However, this interpretation raises several questions. First, it seemingly contradicts findings in ARC that RAR activation leads to increased expression of the GLUT4 mRNA. However, it should be noted that the RAR 
agonist atRA and TTNPB failed to raise the GLUT4 mRNA content in NRC, perhaps indicating developmental changes in RAR expression. Second, RXR functions as an obligatory dimer, either with itself or with another member of the nuclear receptor/transcription factor family, such as RAR or peroxisome proliferator-activated receptors (PPARs). The identity of the RXR partner remains to be determined. RAR is probably not the partner of RXR in the transcription experiments as neither atRA nor TTNPB stimulated transcription from the glut4 promoter. It is also unlikely that PPAR are involved given that selective stimulation of PPAR $\alpha$, PPAR $\gamma$ or PPAR $\beta / \delta$ in ARC does not modify GLUT4 expression (C. Pellieux, personal communication).

In the remodeling-hypertrophy model, retinoids were able to alleviate some, but not all, features of the hypertrophic phenotype. Although myofibrillar organization was improved in ARC treated with atRA and 9-cisRA, the increase in cell size was not blunted. With regard to the expression of ANF, treatment with retinoids blunted the initial rise in ANF expression, but failed to curb the large increase observed during the development of hypertrophy. Although the initial rise of ANF expression was independent of the concentration of FCS in the culture, the following massive overexpression was only observed in high FCS culture conditions (C. Pellieux, personal communication). This observation is, therefore, similar to that of Zhou et al. [44] who found that, in neonatal rat cardiomyocytes, RA prevented hypertrophy and ANF expression induced by phenylephrine or endothelin, but not by FCS. Indeed, in ARC isolation triggers MAP kinase pathways such as ERK1/2 and p38 MAPK [18] that are responsive to phenylephrine and endothelin in NRC. In contrast to the dedifferentiation-redifferentiation model, in the remodeling-hypertrophy model, only 9-cisRA was able to stimulate GLUT4 expression. It is possible that the complement of RAR and RXR expressed in the two models is different and varies with the time in culture.

\section{Study limitations}

One major limitation of the adult rat cardiomyocytes (ARC) model is that ARC are not amenable to conventional transfection techniques. We, therefore, had to resort to neonatal rat cardiomyocytes (NRC) for studies involving transfection of a reporter gene under the control of the glut4 promoter. In doing so, we assumed that the regulation of GLUT4 expression by RA was similar in ARC and NRC; this assumption is partially supported by the data of Fig. 6A.

The issue of the relative implication of RAR and RXR in the regulation of GLUT4 expression is not entirely resolved by the experiments in this study. Experiments with pharmacological inhibitors of either RAR or RXR could possibly have helped clarify this point. However, to the best of our knowledge, none were commercially available when this study was performed.

\section{Conclusion}

In conclusion, retinoic acids and particularly the 9-cis isoform are able to restore GLUT4 expression in dedifferentiated and hypertrophied adult rat cardiac myocytes. This effect occurs in a context of improved differentiation of the cardiac myocytes and involves transcription form the glut4 promoter. The causal relationship between GLUT4 expression and the differentiation phenotype, if any, remains to be investigated.

\section{References}

1. Abel ED, Kaulbach HC, Tian R, Hopkins JCA, Duffy J, Doetschman T, Minnemann T, Boers M-E, Hadro E, Oberste-Berghaus C, Quist W, Lowell BB, Ingwall JS, Kahn BB (1999) Cardiac hypertrophy with preserved contractile function after selective deletion of GLUT4 from the heart. J Clin Invest 104:1703-1714

2. Allenby G, Bocquel M, Saunders M, Kazmer S, Speck J, Rosenberger M, Lovey A, Kastner P, Grippo J, Chambon P, Levin A (1993) Retinoic Acid Receptors and Retinoid X Receptors: Interactions with Endogenous Retinoic Acids. Proc Natl Acad Sci USA 90:30-34

3. Aranda A, Pascual A (2001) Nuclear Hormone Receptors and Gene Expression. Physiological Reviews 81:1269-1304
4. Bartelds B, Gratama J-WC, Knoester H, Takens J, Smid GB, Aarnoudse JG, Heymans HSA, Kuipers JRG (1998) Perinatal changes in myocardial supply and flux of fatty acids, carbohydrates, and ketone bodies in lambs. Am J Physiol 274:H1962-H1969

5. Claycomb W, Palazzo M (1980) Culture of the terminally differentiated adult cardiac muscle cell: a light and scanning electron microscope study. Dev Biol 80:466-482

6. de Paiva SAR, Zornoff LAM, Okoshi MP, Okoshi K, Matsubara LS, Matsubara BB, Cicogna AC, Campana AO (2003) Ventricular remodeling induced by retinoic acid supplementation in adult rats. Am J Physiol 284:H2242-H2246
7. Eppenberger HM, Hertig C, Eppenberger-Eberhardt M (1994) Adult rat cardiomyocytes in culture. A model system to study the plasticity of the differentiated cardiac phenotype at the molecular and cellular levels. Trends Cardiovasc Med 4:187-193

8. Eppenberger-Eberhardt M, Flamme I, Kurer V, Eppenberger HM (1990) Reexpression of $\alpha$-smooth muscle actin isoform in cultured adult rat cardiomyocytes. Dev Biol 139:269-278

9. Habara-Ohkubo A (1996) Differentiation of beating cardiac muscle cells from a derivative of P19 embryonal carcinoma cells. Cell Struct Funct 21:101-110 
10. Jeremy RW, Ambrosio G, Pike MM, Jacobus WE, Becker LC (1993) The functional recovery of post-ischemic myocardium requires glycolysis during early reperfusion. J Mol Cell Cardiol 25:261-276

11. Jeremy RW, Koretsune Y, Marban E, Becker LC (1992) Relation between glycolysis and calcium homeostasis in postischemic myocardium. Circ Res 70:1180-1190

12. Jiang H, Penner JD, Beard RL, Chandraratna RAS, Kochhar DM (1995) Diminished teratogenicity of retinoid X receptor-selective synthetic retinoids. Biochem. Pharmacol. 50:669-676

13. Kaestner KH, Christy RJ, McLenithan JC, Braiterman LT, Cornelius P, Pekala PH, Lane MD (1989) Sequence, tissue distribution, and differential expression of mRNA for a putative insulin-responsive glucose transporter in mouse 3T3-L1 adipocytes. Proc Natl Acad Sci USA 86:3150-3154

14. Katz EB, Stenbit AE, Hatton K, DePinho R, Charron MJ (1995) Cardiac and adipose tissue abnormalities but not diabetes in mice defficient in GLUT4. Nature 377:151-155

15. Lopaschuk GD, Spafford MA, Marsh DR (1991) Glycolysis is predominant source of myocardial ATP production immediately after birth. Am J Physiol 261:H1698-H1705

16. Lu L, Yao T, Zhu Y-Z, Huang G-Y, Cao Y-X, Zhu Y-C (2003) Chronic all-trans retinoic acid treatment prevents medial thickening of intramyocardial and intrarenal arteries in spontaneously hypertensive rats. Am J Physiol 285:H1370-H1377

17. Ménard C, Pupier S, Mornet D, Kitzmann M, Nargeot J, Lory P (1999) Modulation of L-type Calcium Channel Expression during Retinoic Acid-induced Differentiation of H9C2 Cardiac Cells. Journal of Biological Chemistry 274:29063-29070

18. Montessuit C, Papageorgiou I, Palma T, Lerch R (2004) MEF 2 regulates the transcription of GLUT4 in cardiac myocytes. J Mol Cell Cardiol 36:747

19. Montessuit C, Papageorgiou I, Remondino-Müller A, Tardy I, Lerch R (1998) Post-ischemic stimulation of 2-deoxyglucose uptake in rat myocardium: role of translocation of GLUT-4. J Mol Cell Cardiol 30:393-403

20. Montessuit C, Rosenblatt-Velin N, Papageorgiou I, Campos L, Pellieux C, Palma T, Lerch R (2004) Regulation of glucose transporters expression in cardiac myocytes: p38 MAPK is a strong inductor of GLUT4. Cardiovasc Res 64:94-104
21. Nagao M, Parimoo B, Tanaka K (1993) Developmental, nutritional, and hormonal regulation of tissue-specific expression of the genes encoding various acyl-CoA dehydrogenases and $\alpha$-subunit of electron transfer flavoprotein in rat. J Biol Chem 268:24114-24124

22. Paternostro G, Clarke K, Heath J, Seymour A-M, Radda GK (1995) Decreased GLUT-4 mRNA content and insulin-sensitive deoxyglucose uptake show insulin resistance in the hypertensive rat heart. Cardiovasc Res 30:205-211

23. Paternostro G, Pagano D, Gnecchi-Ruscone T, Bonser R, Camici P (1999) Insulin resistance in patients with cardiac hypertrophy. Cardiovasc. Res. 42:246-253

24. Postic C, Leturque A, Printz RL, Maulard P, Loizeau M, Granner DK, Girard J (1994) Development and regulation of glucose transporter and hexokinase expression in rat. Am J Physiol 266:E548-E559

25. Razeghi P, Young ME, Alcorn JL, Moravec CS, Frazier OH, Taegtmeyer $\mathrm{H}$ (2001) Metabolic Gene Expression in Fetal and Failing Human Heart. Circulation 104:2923-2931

26. Richardson JM, Pessin JE (1993) Identification of a skeletal muscle-specific regulatory domain in the rat GLUT4/musclefat gene. J Biol Chem 268:21021-21027

27. Rosenblatt-Velin N, Lerch R, Papageorgiou I, Montessuit C (2004) Insulin resistance in adult cardiomyocytes undergoing dedifferentiation: role of GLUT4 expression and translocation. FASEB J 18:872-874

28. Rosenblatt-Velin N, Montessuit C, Papageorgiou I, Terrand J, Lerch R (2001) Postinfarction heart failure in rats is associated with upregulation of GLUT-1 and downregulation of genes of fatty acid metabolism. Cardiovasc Res 52:407-416

29. Sambrook J, Fritsch EF, Maniatis T (1989) Molecular cloning: a laboratory manual. Cold Spring Harbor Laboratory Press, New York

30. Sivitz WI, Lee EC (1991) Assessment of glucose transporter gene expression using the polymerase chain reaction. Endocrinology 128:2387-2394

31. Sleeman M, Zhou H, Rogers S, Ng K, Best J (1995) Retinoic acid stimulates glucose transporter expression in L6 muscle cells. Mol Cell Endocrinol 108:161-167

32. Studelska DR, Campbell C, Pang S, Rodnick KJ, James DE (1992) Developmental expression of insulin-regulatable glucose transporter GLUT-4. Am J Physiol 263:E102-E106

33. Tardy-Cantalupi I, Montessuit C, Papageorgiou I, Remondino-Müller A, Assimacopoulos-Jeannet F, Morel DR, Lerch $R$ (1999) Effect of transient ischemia on the expression of glucose transporters GLUT- 1 and GLUT- 4 in rat myocardium. J Mol Cell Cardiol 31:1143-1155
34. Terami H, Hidaka $\mathrm{K}$, Katsumata T, Iio A, Morisaki T (2004) Wnt11 facilitates embryonic stem cell differentiation to Nkx2.5-positive cardiomyocytes. Biochem. Biophys Res Commun 325:968-975

35. Thorburn J, McMahon M, Thorburn A (1994) Raf-1 kinase activity is necessary and sufficient for gene expression changes but not sufficient for cellular morphology changes associated with cardiac myocyte hypertrophy. J Biol Chem 269:30580-30586

36. Tian R, Abel ED (2001) Responses of GLUT4-Deficient Hearts to Ischemia Underscore the Importance of Glycolysis. Circulation 103:2961-2966

37. Urbach J, Rando RR (1994) Thiol dependent isomerization of all-trans-retinoic acid to 9-cis-retinoic acid. FEBS Lett 351:429-432

38. Wang C, Hu S-M (1991) Developmental regulation in the expression of rat heart glucose transporters. Biochem. Biophys Res Commun 177:1095-1100

39. White SM, Constantin PE, Claycomb WC (2004) Cardiac physiology at the cellular level: use of cultured HL-1 cardiomyocytes for studies of cardiac muscle cell structure and function. American Journal of Physiology 286:H823-H829

40. Wobus AM, Kaomei G, Shan J, Wellner M-C, Rohwedel J, Guanju J, Fleischmann B, Katus HA, Hescheler J (1997) Retinoic Acid Accelerates Embryonic Stem CellDerived Cardiac Differentiation and Enhances Development of Ventricular Cardiomyocytes. J Mol Cell Cardiol: 29

41. Wu J, Garami M, Cheng T, Gardner DG (1996) $1,25(\mathrm{OH})_{2}$ Vitamin $\mathrm{D}_{3}$ and Retinoic Acid Antagonize Endothelinstimulated Hypertrophy of Neonatal Rat Cardiac Myocytes. J Clin Invest 97:1577-1588

42. Young LH, Ren-fu Y, Russell R, Hu X, Caplan M, Ren J, Shulman GI, Sinusas AJ (1997) Low-flow ischemia leads to translocation of canine heart GLUT-4 and GLUT-1 glucose transporters to the sarcolemma in vivo. Circulation 95:415-422

43. Zandstra P, Bauwens C, Yin T, Liu Q, Schiller H, Zweigerdt R, Pasumarthi K, Field L (2003) Scalable production of embryonic stem cell-derived cardiomyocytes. Tissue Eng 9:767-778

44. Zhou M, Sucov H, Evans R, Chien K (1995) Retinoid-dependent pathways suppress myocardial cell hypertrophy. Proc Natl Acad Sci USA 92:7391-7395 